\title{
Anesthetic complications in children with mucopolysaccharidosis
}

\section{Complicaciones anestésicas en niños con mucopolisacaridosis}

\author{
Luz María Sánchez-Sánchez, M.D.,* Jesús Morgado-Pérez, M.D., ${ }^{\ddagger}$ \\ Gustavo Edén Gutiérrez-Mendoza, M.D., ${ }^{\ddagger}$ Thor Gustavo Nissen-Torres, M.D. ${ }^{\S}$
}

How to cite: Sánchez-Sánchez LM, Morgado-Pérez J, Gutiérrez-Mendoza GE, Nissen-Torres TG. Anesthetic complications in children with mucopolysaccharidosis. Rev Mex Anestesiol. 2021; 44 (3): 184-189. https://dx.doi.org/10.35366/99665

\begin{abstract}
Introduction: A high percentage of mucopolysaccharidosis patients require surgery at some point. Common features like respiratory limitations and cardiovascular disease pose a high anesthetic risk. We describe the prevalence of anesthetic complications in our institution. Material and methods: Patients' medical history and reported surgery data from 18 eligible records were reviewed from a total of 29 mucopolysaccharidosis diagnosed children registered between the years 1999 to 2019 at a hospital in Mexico. Results: Median age was 11 years. 12 patients were type I, two type II, three type IV, and one type VI. Intravenous premedication was administered in $69.5 \%$ and induction was intravenous in $91.3 \%$ of the surgical procedures. Orotracheal intubation was the first attempted anesthetic method in $47.8 \%$ and a laryngeal mask in another $47.8 \%$. Bronchospasm was the most frequent complication in $17.4 \%$ followed by difficult intubation in $13.1 \%$. Conclusions: Bronchospasm was the most prevalent complication. A higher CormackLehane grade was primarily related. The most prevalent concomitant risk factors were short neck and restrictive chest rendering airway management difficult in comparison to the general population.
\end{abstract}

RESUMEN. Introducción: Un alto porcentaje de pacientes con mucopolisacaridosis requieren cirugía en algún momento. Algunas características comunes como alteraciones respiratorias y enfermedades cardiovasculares constituyen un alto riesgo anestésico. Describimos la prevalencia de las complicaciones anestésicas en nuestra institución. Material y métodos: Fueron revisados los antecedentes y los datos quirúrgicos de 18 pacientes elegibles, extraídos de un total de 29 expedientes de niños con mucopolisacaridosis registrados entre los años 1999 y 2019 en un hospital de México. Resultados: La mediana de edad fue de 11 años. Doce pacientes fueron de tipo I, dos tipo II, tres tipo IV y uno tipo VI. La premedicación intravenosa se administró en 69.5\% y la inducción fue intravenosa en 91.3\% de los procedimientos quirúrgicos. El primer método anestésico intentado fue la intubación orotraqueal en $47.8 \%$ y la máscara laríngea en $47.8 \%$. El broncoespasmo fue la complicación más frecuente en $17.4 \%$, seguida de una intubación difícil en 13.1\%. Conclusiones: El broncoespasmo fue la complicación más observada relacionada, primordialmente, con un grado Cormack-Lehane más alto. Los factores de riesgo concomitantes más frecuentes fueron el cuello corto y las restricciones torácicas, lo que dificulta en mayor grado el manejo de las vías respiratorias en comparación con la población general.

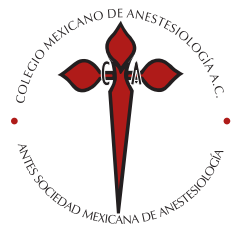

Keywords:

Mucopolysaccharidosis, airway management, anesthetic complications.

\section{Palabras clave:}

Mucopolisacaridosis, manejo de vía aérea, complicaciones anestésicas.

* Pediatrician.

‡ Anesthesiologist.

$\S$ Research and Clinical Services.

Department of Pediatrics and Department of Anesthesiology at Hospital de Especialidades UMAE 25, IMSS, Monterrey, N.L. Department of Research and Clinical Services at SPRIM Americas Mexico, Mexico City, Mexico.

\section{Correspondence:}

Luz María SánchezSánchez

Salamanca 5907, Cumbres

Santa Clara, 64349,

Monterrey, N.L., Mexico.

E-mail: Dra.LSanchez@kidsdoctor.mx

Received: 25-06-2020

Accepted: 20-10-2020

\section{Abbreviations:}

MPS = Mucopolysaccharidosis.

OSAS = Obstructive sleep

apnea syndrome.

UMAE 25 = Unidad Médica de

Alta Especialidad No. 25.

\section{INTRODUCTION}

M ucopolysaccharidosis (MPS) represents a group of rare lysosomal storage diseases associated with several clinical manifestations. High prevalence of airway obstruction and restrictive lung diseases in combination with cardiovascular manifestations pose a high anesthetic risk for these patients. A high percentage of MPS patients require surgery at some point. Data from the Hunter Outcome Survey ( $\mathrm{N}=527$ ) showed surgical interventions in $83.7 \%$ of MPS II patients ${ }^{(1)}$. Approximately $75 \%$ of patients in the MPS I
Registry reported at least 1 surgery ${ }^{(2)}$. In Mexico, MPS patients can access relevant information on their disease through the corresponding chapter of the Rare Diseases National Federation (http://www.femexer.org/). No Mexican statistical data could be found on the incidence of surgeries performed in MPS patients. Typical anesthetic problems include airway obstruction after induction or extubation, intubation difficulties or failure, possible emergency tracheostomy, and cardiovascular or cervical problems ${ }^{(3)}$. Trans-anesthetic obstruction at nasopharyngeal, oropharyngeal, laryngeal, and subglottic levels may occur due to many factors, such as a large 
tongue, tonsillar or adenoidal hypertrophy, thick and copious secretions of chronic infections, narrow and flattened trachea, facial-skeletal deformities, anterior and cephalic shift of the larynx, short and immobile neck, limited temporomandibular and cervical spine movements, and cervical instability ${ }^{(4)}$. A recent study including 17 MPS patients reported difficult mask ventilation in 20/141 anesthetics (14.2\%), difficult intubation in $25 \%$, and failed intubation in $1.6 \%(5)$.

A thorough preoperative assessment of the cardiovascular, pulmonary, and neurological systems is of great importance, as well as establishing which type of MPS is involved. MPS types I, IV, and VI pose an increased surgical risk ${ }^{(6)}$. To mitigate risks, the choice of anesthetic technique should be conducted by experienced anesthesiologists with expertise in using advanced airway intubating devices, whether it will be intravenous, inhalational induction, or intubation with a fiberscope in an awake patient under topical anesthesia ${ }^{(7)}$. The use of fiberoptic intubation techniques and the introduction of laryngeal masks have reduced the need for tracheostomy in difficult airways and failed intubation procedures ${ }^{(8)}$. The preparation for extubation should include the use of intraoperative steroids, the complete emergence from muscle relaxant, and nasopharyngeal airway placement to reduce upper airway obstruction after extubation ${ }^{(3,4,6,7)}$.

Complications during anesthesia include apnea, bronchospasm, cyanosis, respiratory disease, failed extubation promoted by abundant oral secretions, rib cage stiffness, and heart and respiratory failure particularly in types I and VI. Recognition of these risk factors allows the anesthesiologist to be prepared and properly manage possible problems that may arise during or after the procedure ${ }^{(7,8)}$.

This study was conducted at the Hospital de Especialidades No. 25 (UMAE 25), a public third-level hospital in northeastern Mexico. The hospital is part of the Instituto Mexicano del Seguro Social, a Social Security institution that affiliates employees working in the private industry in Mexico. It is located in the city of Monterrey, Nuevo Leon. The objective of the study was to retrospectively describe the prevalence of perioperative complications in children with MPS attending the institution.

\section{MATERIAL AND METHODS}

After approval was granted by the Local Health Research Committee (with registration No. R20181901066, dated 16 Oct 2018), an observational, descriptive, retrospective study was conducted following quality, ethical, and research local guidelines and national regulations. Written informed consent was waived due to the retrospective design. Medical records of the 29 registered MPS patients under 18 years of age with enzyme confirmed diagnosis treated at UMAE 25 between the years 1999 to 2019 were assessed. Patients with a history of tracheostomy or incomplete trans anesthetic registry and/ or postanesthetic note were excluded. 18 (62.0\%) patients fulfilled eligibility criteria and were included for review.

Demographic data, relevant medical history, ASA Physical Status evaluation, MPS type, concomitant risk factors, and musculoskeletal pathology data were recorded. The premedication, induction technique, method of airway management used, difficulty with the airway or intubation, and any complications during anesthesia or the recovery period were obtained from the anesthetic chart.

Data were described in absolute numbers, percentages, and measures of central tendency.

\section{RESULTS}

\section{Demographic data and clinical condition}

Patients' median age was 11 years (range 2-18 years). 8 (44.4\%) were male and 10 (55.6\%) were female. Out of the 18 included patients, 12 (66.7\%) were MPS type I, 2 (11.1\%) were MPS type II, 3 (16.7\%) were MPS type IV and 1 (5.5\%) was MPS type VI. 6 patients presented with a heart valve condition, mainly stenosis, thickening, and insufficiency of the mitral valve, out of which 5 were type I and 1 type II. Lung problems and severe obstructive sleep apnea syndrome (OSAS) were documented in 7 patients, out of which 6 were MPS I and 1 MPS II. Intellectual disability was present in 10 patients, out of which 9 were MPS I and one MPS II. 2 patients had mild musculoskeletal manifestations as their phenotypes were attenuated (one type I and one type II), the rest varied. All patients presented one or more risk factors associated with airway difficulties. $100 \%$ had a short neck and over $80 \%$ had restrictive chest (Table 1).

\section{Surgical procedures}

A total of 23 anesthetic procedures were reviewed, as some patients required more than one surgery at different times. 11 (47.8\%) were for port catheter placement for enzyme replacement therapy and 5 (21.7\%) were tonsillectomy (with concomitant myringotomy in 3). Anesthesia was given for corneal transplantation on 3 occasions (13.1\%). A ventriculoperitoneal shunt, a cervical laminectomy, a posterior arch resection, and an umbilical hernioplasty were also performed.

\section{Anesthetic care}

All patients had ASA III classification due to the clinical characteristics of patients with MPS. Premedication with midazolam was administered in 16 (69.5\%) surgical procedures and the elected route was intravenous. No premedication-related complications were reported. 
Intravenous induction was performed in 21 (91.3\%) anesthetic procedures where propofol and fentanyl were used. Inhaled induction occurred in the other 2 (8.7\%), in which oxygen and sevoflurane were used.

Mask ventilation was successful in 21 (91.3\%) anesthetic procedures. Orotracheal intubation was the first attempted anesthetic method in 11 (47.8\%). The number of laryngoscopies required to achieve orotracheal intubation was one or two in 7 (63.6\%) patients and three or more laryngoscopies were required in the other 2 (18.2\%). Out of these 9 successful attempts, 6 were Cormack-Lehane grade II and 3 grade III. Intubation failed in the other 2 (18.2\%) patients. These cases were Cormack-Lehane grade IV. In one patient, intubation was achieved with the fiber optic bronchoscope, and the other intubation was not achieved and a laryngeal mask was used. Laryngeal mask (supraglottic device) was the first attempted method in the other 11 (47.8\%). In one patient it was the alternative attempted method due to failed orotracheal intubation, as described above. Fiber optic bronchoscopy was used as the first attempted method in one procedure.

The most used anesthetic agent was sevoflurane administered in 22 (95.7\%).

\section{Perioperative complications}

No complications were reported in 11 (47.8\%) of the anesthetic procedures. Bronchospasm was the most frequent complication occurring in $4(17.4 \%)$ patients. Other complications were 3 (13.1\%) difficult intubations, 2 (8.7\%) failures of intubation, 2 (8.7\%) laryngeal edemas, and 1 (4.3\%) poor secretion control case. Of the two laryngeal edema cases, one was due to multiple attempts of orotracheal intubation resulting in admission to an intensive care unit for surveillance and management with anti-inflammatories achieving good evolution (Table 2).

\section{DISCUSSION}

\section{Surgery in MPS patients}

It is important to consider the risk-benefit ratio before exposing an MPS patient to a surgical anesthetic procedure. Anesthetic risk factors must be carefully evaluated ${ }^{(5,8-13)}$.

Mendelson reported the results of 527 patients with MPS II. Most common surgical interventions where tympanostomies, inguinal repair, and release of carpal tunnel, performed in a greater proportion of the study population than the general population ${ }^{(1)}$. A study by Arn, Bruce, et al. analyzed the frequency of airwayrelated surgeries among 1,041 patients with MPS I. From the 698 airwayrelated surgeries reported, over $80 \%$ were adenoidectomy/tonsillectomy, followed by tracheostomy and bronchoscopy ${ }^{(14)}$. In patients with MPS IVA, skeletal system affections are prevalent, spinal cord compression is

Table 1: Clinical characteristics of patients and surgical procedures performed.

\begin{tabular}{|c|c|c|c|c|c|}
\hline $\begin{array}{l}\text { Median age in years (range) } \\
\text { No. of females } \\
\text { No. of males }\end{array}$ & $\begin{aligned} & 11(2-18) \\
& 10(55.6 \%) \\
& 8(44.4 \%)\end{aligned}$ & & & & \\
\hline & Type I & Type II & Type IV & Type VI & Total \\
\hline No. of patients & $12(66.7 \%)$ & $2(11.1 \%)$ & $3(16.7 \%)$ & $1(5.5 \%)$ & 18 \\
\hline \multicolumn{6}{|l|}{ Concomitant risk factors } \\
\hline Short neck & 12 & 2 & 3 & 1 & 18 \\
\hline Restrictive chest & 11 & 1 & 3 & 1 & 16 \\
\hline Severe joint manifestations & 10 & 1 & $3^{*}$ & 1 & 15 \\
\hline Severe spinal deformities & 8 & 1 & 3 & 1 & 13 \\
\hline Intellectual disability & 9 & 1 & - & - & 10 \\
\hline Severe sleep apnea & 6 & 1 & - & - & 7 \\
\hline Heart valve condition & 5 & 1 & - & - & 6 \\
\hline No. of procedures & $17(73.9 \%)$ & $2(8.7 \%)$ & $3(13.1 \%)$ & $1(4.3 \%)$ & 23 \\
\hline \multicolumn{6}{|l|}{ Procedure } \\
\hline Port catheter & 9 & 2 & - & - & $11(47.8 \%)$ \\
\hline Tonsillectomy** & 4 & - & 1 & - & $5(21.7 \%)$ \\
\hline Corneal transplantation & 3 & - & - & - & $3(13.1 \%)$ \\
\hline Ventriculoperitoneal shunt & 1 & - & - & - & $1(4.3 \%)$ \\
\hline Cervical laminectomy & - & - & 1 & - & $1(4.3 \%)$ \\
\hline Posterior arch resection & - & - & 1 & - & $1(4.3 \%)$ \\
\hline Umbilical hernioplasty & - & - & - & 1 & $1(4.3 \%)$ \\
\hline
\end{tabular}

* All 3 type IV patients had hypermobile joints and the other types had joint stiffness. ** 3 patients had simultaneous myringotomy, 2 type I and 1 type 4. 


\begin{tabular}{|c|c|c|}
\hline \multicolumn{3}{|c|}{$\begin{array}{l}\text { Table 2: Anesthetic management and } \\
\text { anesthesia-related complications. }\end{array}$} \\
\hline & Number & $\%$ \\
\hline Anesthetic procedures & 23 & 100.0 \\
\hline ASA III classification & 23 & 100.0 \\
\hline Intravenous premedication (midazolam) & 16 & 69.5 \\
\hline \multicolumn{3}{|l|}{ Anesthetic induction } \\
\hline Intravenous* & 21 & 91.3 \\
\hline Inhaled ${ }^{\ddagger}$ & 2 & 8.7 \\
\hline \multicolumn{3}{|l|}{ Ventilation with mask } \\
\hline Easy & 21 & 91.3 \\
\hline Difficult $\$$ & 2 & 8.7 \\
\hline \multicolumn{3}{|l|}{ First attempted anesthetic method } \\
\hline Orotracheal tube & 11 & 47.8 \\
\hline \multicolumn{3}{|l|}{ - Successful" 9 (81.8\%) } \\
\hline \multicolumn{3}{|l|}{$\begin{array}{l}\text { [7 (63.6\%) with one or two } \\
\text { laryngoscopies; } 2(18.2 \%) \text { with } \\
\text { three or more] } \\
\text { - Failure** } 2(18.2 \%)\end{array}$} \\
\hline Supraglottic device & 11 & 47.8 \\
\hline Fiber-optic bronchoscope & 1 & 4.3 \\
\hline \multicolumn{3}{|l|}{ Anesthetic agent } \\
\hline Sevoflurane & 22 & 95.7 \\
\hline Desflurane & 1 & 4.4 \\
\hline \multicolumn{3}{|l|}{ Anesthetic complications } \\
\hline No complications & 11 & 47.8 \\
\hline Bronchospasm & 4 & 17.4 \\
\hline Difficult Intubation & 3 & 13.1 \\
\hline Failure of intubation & 2 & 8.7 \\
\hline Laryngeal edema & 2 & 8.7 \\
\hline Poor secretion control & 1 & 4.3 \\
\hline
\end{tabular}

* Propofol and fentanyl were used. ${ }^{*}$ Oxygen and sevoflurane were used.

$\S$ One with MPS I, could not be ventilated, and the other with MPS IV, presented an obstruction. " 6 were Cormack-Lehane grade II and 3 grade III.

${ }^{*}$ Both were Cormack-Lehane grade IV where alternative methods were fiber optic bronchoscope in one and laryngeal mask (supraglottic device) in the other.

frequent, and affected individuals undergo multiple surgeries to alleviate serious orthopedic complications ${ }^{(15)}$. In our case series, the most common procedures were port catheter placement, tonsillectomy, and corneal transplant. Other procedures reported were two spine surgeries, one hernia repair, and one ventriculoperitoneal shunt. The procedures patients underwent in our study are in alignment with the ones reported by other authors, representing frequent comorbidities associated with MPS.

Thoracic cage abnormalities predispose to the development of respiratory restrictive diseases, which can often lead to the development of OSAS, pulmonary hypertension, cor pulmonale, and eventually respiratory failure ${ }^{(8,13,15,16)}$. In our study, severe OSAS was found in 7 patients, most with a diagnosis of type I MPS.

\section{Perioperative care}

In a literature review article regarding anesthetic care in patients with MPS, Clark, et al. recommend not to underestimate perioperative evaluation as substantial challenges for airway management may be expected ${ }^{(7)}$. Difficulties may appear before, during, and after anesthetic procedures and should ideally be closely monitored postsurgery. Recommendations for the management of MPS VI, endorse that pre, intra, and postoperative care should be supervised by an anesthetist with experience in this disorder and/or in complex airway management for all procedures requiring general anesthesia, conscious or deep sedation. Intensive care support should be available along with a qualified team capable of performing emergency tracheotomy, if required. Assessment of the risks and benefits is recommended to take place with the patient and family as well. They recommend the use of techniques that allow maintenance of the neutral neck position, including the use of laryngeal mask airway, particularly for short-duration procedures $^{(17)}$.

The laryngeal mask is a common supraglottic device used, with proved usefulness in children with MPS both as a primary airway device as well as an air duct, by facilitating ventilation before intubation with a bronchoscope $\mathrm{e}^{(4,8,15,16)}$. In our case series, the laryngeal mask was used as a first anesthetic attempt for short-duration procedures in 11 (47.8\%) reported patients. Nevertheless, anatomic abnormalities and excessive secretions may hamper its use $\mathrm{e}^{(5)}$. Walker, Belani, et al. concluded that insertion of a laryngeal mask will often improve ventilation either as a first choice or to facilitate intubation with fiber optic bronchoscope $^{(3)}$. In our study, the fiber optic bronchoscope was the firstchoice method for only one (MPS I) patient representing $4.3 \%$ of the reviewed population, allowing adequate intubation without complications. However, it was decided to admit the patient into the intensive care unit to allow controlled extubation.

\section{Intravenous premedication}

Any sedation, either inhaled or intravenously administrated, may cause severe hypoxemia due to commonly associated airway obstruction. Although midazolam may cause respiratory depression it has been used successfully. Midazolam has the advantage that it can be reversed with the administration of flumazenil if necessary ${ }^{(3)}$. In our study, premedication was administered in 16 (69.5\%) of the anesthetic procedures and only midazolam was used for its sedative, anxiolytic, and amnestic properties with no complications.

\section{Intubation}

Difficulties in airway management and intubation are widely documented in MPS patients. Moretto, et al. found that direct 
laryngoscopy, videolaryngoscope, or fiberoptic bronchoscope have been used as intubation techniques in patients with MPS $\mathrm{IV}^{(18)}$. A study by Walker, Darowski, et al. which included 34 patients who underwent 89 anesthetic procedures for 110 operations, showed intubation difficulties in $11(37.9 \%)$ out of 29 patients who were intubated and failed intubation in 3 $(10.3 \%)$ of them ${ }^{(8)}$. In another study, 54 children with MPS were subject to 232 anesthetic procedures. Intubation was elected as the first choice in 65 anesthetics of which $19(29 \%)$ had difficult intubation and $3(4.6 \%)$ failed and a laryngeal mask was used as the rescue procedure ${ }^{(19)}$. In our study, orotracheal intubation was the first choice in $11(47.8 \%)$ cases. Intubation failed in 2 (18.2\%). In one type I, 18yearold MPS patient with a CormackLehane grade IV, multiple direct laryngoscopies were performed followed by the use of a supraglottic device to improve oxygenation. Intubation was finally performed under fiberoptic bronchoscopy. A second patient was an 11yearold female with MPS I. Intubation attempts failed multiple times. A supraglottic device (laryngeal mask) was placed as rescue ventilation.

\section{Complications}

The most severe anesthetic complications occurring during surgery in MPS patients are associated with airway obstruction, difficulty in ventilation and oxygenation, and those associated with cardiovascular diseases which pose a great challenge to the anesthesiologist, in addition to putting the patient's life at risk. The phenotypic manifestations such as coarse facies, large tongue, tonsillar hypertrophy, adenoidal hypertrophy, chronic respiratory tract infections, narrow and flat trachea, facialskeletal deformities, anterior and cephalic displacement of the larynx, short and mobile neck, limitation of movement of the temporomandibular joint and cervical instability make it difficult for the experienced anesthesiologist to manage the airway $^{(3,4,6-8,16)}$. In our study, anesthetic complications were reported in 12 of the cases being bronchospasm and intubation difficulties most prevalent.

\section{Study limitations}

In our report, outcomes after the recovery period were not investigated with the risk of underestimating potential longterm anesthetic complications. MPS specific therapy administration was not investigated as it may be better assessed in prospective longitudinal studies. Recognized possible selection and information biases may have occurred as in other retrospective designed studies. Further studies are necessary to evaluate anesthetic procedures in MPS patients.

\section{CONCLUSIONS}

Anesthetic complications are seen more frequently in MPS patients and are related to the different risk factors present as part of the clinical and anatomical features of the disease. In this series, $100 \%$ of the patients presented a short neck, over $80 \%$ restrictive chest along with other less frequent risk factors associated with airway difficulties. Bronchospasm was the most frequent single complication in $17.4 \%$ of the cases followed by intubation difficulties in $13.1 \%$ of the cases, primarily related to a higher Cormack-Lehane grade.

\section{ACKNOWLEDGMENT}

The authors would like to thank Erika Barron, MD, and Debora Mesojedovas, PharmD for contributions, and BioMarin Mexico (BMRN Mexico, S.R.L. de C.V.), which sponsored the preparation of this manuscript with Medical Writer and Translation services. BioMarin does not play role in the results or the opinion of this paper.

\section{REFERENCES}

1. Mendelsohn NJ, Harmatz P, Bodamer O, et al. Importance of surgical history in diagnosing mucopolysaccharidosis type II (Hunter syndrome): data from the Hunter Outcome Survey. Genet Med. 2010;12:816-822.

2. Arn P, Wraith JE, Underhill L. Characterization of surgical procedures in patients with mucopolysaccharidosis type I: findings from the MPS I Registry. J Pediatr. 2009;154:859-64.e3. doi: 10.1016/j. jpeds.2008.12.024.

3. Walker R, Belani KG, Braunlin EA, et al. Anaesthesia and airway management in mucopolysaccharidosis. J Inherit Metab Dis. 2013;36:211-219.

4. Arn P, Whitley C, Wraith JE, et al. High rate of postoperative mortality in patients with mucopolysaccharidosis I: findings from the MPS I Registry. J Pediatr Surg. 2014;47:477-484.

5. Frawley G, Fuenzalida D, Donath S, Yaplito-Lee J, Peters H. A retrospective audit of anesthetic techniques and complications in children with mucopolysaccharidoses. Paediatr Anaesth. 2012;22:737-744. doi: 10.1111/j.1460-9592.2012.03825.x.
6. Pedersen T, Steinmetz H. Mucopolysaccharidoses and anaesthetic risks. Acta Anaesthesiol Scand. 1987;31:214-218.

7. Clark B, Sprung J, Weingarten T, Warner M. Anesthesia for patients with mucopolysaccharidoses: a comprehensive review of the literature with emphasis on airway management. Bosn J Basic Med Sci. 2018;18:1-7.

8. Walker RW, Darowski M, Morris P, Wraith JE. Anaesthesia and mucopolysaccharidoses. A review of airway problems in children. Anaesthesia. 1994;49:1078-1084.

9. Leighton SE, Papsin B, Vellodi A, Dinwiddie R, Lane R. Disordered breathing during sleep in patients with mucopolysaccharidoses. Int $\mathrm{J}$ Pediatr Otorhinolaryngol. 2014;58:127-138.

10. Berger KI, Fagondes SC, Giugliani R, et al. Respiratory and sleep disorders in mucopolysaccharidosis. Inherit Metab Dis. 2013;36:201210.

11. Braunlin EA, Harmatz PR, Scarpa M, et al. Cardiac disease in patients with mucopolysaccharidosis: presentation, diagnosis, and management. J Inherit Metab Dis. 2011;34:1183-1197. 
12. Yeung AH, Cowan MJ, Horn B, Rosbe KW. Airway management in children with mucopolysaccharidosis. Arch Otolaryngol Head Neck Surg. 2009;135:73-79.

13. Lin HY, Chen MR, Lin CC, et al. Polysomnographic characteristics in patients with mucopolysaccharidoses. Pediatr Pulmonol. 2010;45:1205-1212.

14. Arn P, Bruce IA, Wraith JE, Travers H, Fallet S. Airway related symptoms and surgeries in patients with mucopolysaccharidosis I. Ann Otol Rhinol Laryngol. 2015;124:198-205.

15. Tomatsu S, Averill LW, Sawamoto K, et al. Obstructive airway in Morquio A syndrome, the past, the present, and the future. Mol Genet Metab. 2016;117:150-156.
16. Hack HA, Walker R, Gardiner P. Anaesthetic implications of the changing management of patients with mucopolysaccharidosis. Anaesth Intensive Care. 2016;44:660-668.

17. Akyol MU, Alden TD, Amartino $\mathrm{H}$, et al. Recommendations for the management of MPS IVA: systematic evidence- and consensus-based guidance. Orphanet J Rare Dis. 2019;14:137.

18. Moretto A, Bosatra MG, Marchesini L, et al. Anesthesiological risks in mucopolysaccharidoses. Ital J Pediatr. 2018;44:116.

19. Scaravilli V, Zanella A, Ciceri V, et al. Safety of anesthesia for children with mucopolysaccharidoses: a retrospective analysis of 54 patients. Pediatr Anesth. 2018;28:436-442. 